\title{
The Integrated Subject
}

\begin{abstract}
"At the Institute of Environmental Architecture, we believe that the architect's primary role is stewardship of the land \& environment. It is in establishing this intrinsic co-relation between human beings and the rest of the natural world that the architect's creative abilities are realized."

- VISION STATEMENT, RACHANA SANSAD INSTITUTE FOR ENVIRONMENTAL ARCHITECTURE
\end{abstract}

As I prepared my first invited talk at Rachana Sansad Institute for Environmental Architecture, my thoughts fixed on the presence of a mutual question between me, in the role of an invited speaker assumed to be worthy of at least an hour of focused attention, and the audience, a group of professional architects assembled as students of environmental architecture. I'd never trained in architecture, and I'd never met the students or faculty member prior to receiving the lecture invitation. Still, as I recounted in the preface, the social and ecological processes foregrounded by culturally charged debates over urban housing, informal shelter, and built space in general had led me to Mumbai, and had, quite unexpectedly, brought me among them as a guest lecturer.

In a fit of nervousness that my lack of an architecture background might prevent me from sufficiently connecting with the students, I found myself settling on the reassurance of a shared, and always contextually informed mutual question: "What does urban ecology mean?" I had used this question to help me organize my analysis of the very case study my lecture would present, and I realized it was also likely shared with this new and unfamiliar audience. For the architecture students, the meaning, or rather meanings, of urban ecology would form the basis for my urban ecology perspective on the Kathmandu case. For me, it was a matter of opening that same question afresh. The architects enrolled in an environmental architecture program presumably sought a kind of training that would enable certain new perspectives, insights, and forms of knowledge. In sharing my work, I thought, perhaps I'd also get a glimpse of the kind of practice that constituted an urban ecology approach in architecture in contemporary Mumbai. 
Beyond the lecture hall, of course, public discourse in South Mumbai buzzed with discussions of the city's new development plan. For this short but animated period, a wide range of the city's publics found it a bit less preposterous to imagine new, more ecological built forms animating the future urban landscape, supplemented, perhaps even generously, by new open spaces. I held that in mind as I made my way to Prabha Devi, climbed the open, airy staircase of Rachana Sansad's main building, and met a group of RSIEA students and faculty for the first time.

At the close of the presentation I invited questions, and several students responded by offering comparative reflections on similar cases in India. A range of design and spatial concerns that were not part of my usual analytical impulses emerged in their detailed critique, giving me a first experiential glimpse of the conceptual and technical dimensions of RSIEA's pedagogy of environmental design. My place as an anthropologist of environmental architecture was thus quite clearly rendered: as I learned from my interlocutors, and was consulted as a sort of "green expert" whilst discussing the ways my expertise fell short, I would also interact with them intellectually and personally. Each encounter made the context even as I sought to document and understand that same context, and I was soon engaged in an ethnography of the training and practice of environmental architecture at RSIEA.

Immediately afterward, I scribbled notes and questions, puzzling over the unfamiliar references and design analytics this group of student professionals brought to bear on my lecture. Specific epistemologies of environmental and social change, and the suite of techniques their profession might apply to the case, seemed to ground their shared expectations of what urban ecology meant in the Kathmandu I'd just discussed. Here, I thought, is perhaps an emergent praxis, an ethnographic understanding of which would depend on attending to the ways that experiencing RSIEA training would codify, activate, and enable a process of translation between a domain generally associated with ecology, and the agentive practice of environmental design.

Soon after that first lecture, this study unfolded. I first focused intensely on experiencing and understanding the pedagogical model employed at RSIEA. By following an entire curricular cycle among the students, I noted the program's form and content, its geographic reach as charted in course study tours that extended far beyond Mumbai, its programmatic flexibility, and its periodic moments of fixity. Completely new to architecture in discipline and practice, I tried to grasp key substantive components, metrics, and the sources (alternately global, regional, and grounded in smaller scale places) from which they derived when invoked in their "environmental" guise. As I attended classes (hurriedly taking notes on topics like thermal comfort and design or the environmental efficiency attributes of India's regional vernacular forms); traveled to places like Chennai, Bangalore, Koorg, and Auroville to study notable examples of regional environmental architecture; and walked the field site for a capstone design assignment in Pali, I was simultaneously a student, a professor, and a researcher. My life and livelihood stood apart from 
the real life stakes of mastering the training and excelling in its aftermath, yet I felt ever more invested, both intellectually and personally, in that same training and its outcomes.

This decidedly unusual field position is not without unresolved complexities. I am not technically trained in architecture or architecture education, and so this book does not pretend to analyze the work of RSIEA architects according to a specific architectural or educational theory. Nor is it an operational assessment intended to gauge the program's relative success or failure. Furthermore, to design the study using RSIEA as its epicenter meant that the singular language of the Institute and much of the profession-English-left many undoubtedly important dimensions of the place, situations, and layers of contests within them either obscured or entirely omitted. The scope of the study, and its potential to address specific questions, then, must be acknowledged as inevitably partial and incomplete. The reader who seeks nuanced analyses of the issues this book cannot address may find it lacking, yet I hope nevertheless convinced to enrich the observations and analysis herein through further attention and study.

In the bustling commercial and residential neighborhood of Prabha Devi, Rachana Sansad hosts a variety of undergraduate and graduate degree programs in several urban and design fields. It was founded in 1960 as an Academy for Architecture, and the school gradually introduced undergraduate and graduate programs in art, interior design, fashion and textiles, construction management, urban and regional planning, photography, music, and event management. Rachana Sansad is a school bustling with young professionals who have returned for advanced study or training, as well as students receiving their first professional degrees. It draws from across Greater Mumbai and Maharashtra, and administers all of its courses in English.

Among its graduate programs is the Rachana Sansad Institute of Environmental Architecture. Although an Academy of Architecture was founded within Rachana Sansad at the time of its inception, the Institute of Environmental Architecture was not established until 2002. From the first semester, which saw an enrollment of just two students, the Institute has grown to host forty students per year. Each undertakes a two-year, master's level degree program and earns a postgraduate degree in Environmental Architecture. A rolling roster of roughly thirty-five visiting instructors joins a core faculty of four-three trained as architects and one as an environmental scientist-to teach courses, lead study tours, conduct field project work, and evaluate student performance. The Institute maintains its official university affiliation with the Yashwantrao Chavan Maharashtra Open University in Nashik.

RSIEA's public vision statement, declared in printed literature and on its website, describes a conceptual mission in which architects regard their professional 
actions as automatic environmental disturbances, much in the way that early characterizations of ecology and nature regarded human activity in terms of perturbation and impact. ${ }^{1}$ The statement reads, in part:

When architects construct buildings, it has an impact on the environment. It affects the ecology of the place, disturbs the flora and fauna, changes the course of water bodies, pollutes the air and depletes finite natural resources. Is such destruction imminent and inevitable? We don't think so. At the Institute of Environmental Architecture, we believe that the architect's primary role is 'stewardship' of the land \& environment. It is in establishing the intrinsic co-relation between human beings and the rest of the natural world that the architect's creative abilities are realized. ${ }^{2}$

At the time of this study, most of the students who enrolled in the RSIEA master's program did so while continuing to work in professional architectural firms and smaller practices. Few could afford to sacrifice their income to devote exclusive attention to the course work, and the schedule of classes is designed with this in mind. Nevertheless, the travel-intensive study tours that form an integral aspect of the program, and are optional, are historically heavily enrolled. Students may not be financially positioned to leave employment completely to undertake the course, but the level of personal and financial commitment was significant, a point to which I will return in a later chapter. ${ }^{3}$

Students come to RSIEA from varied ethnic and religious backgrounds, and faculty often remarked that they hoped that the religious and cultural diversity present in the classes would mirror that of the wider Mumbai population. The male-female ratio slightly favored women at the time of the fieldwork, but by 2017 women constituted $90 \%$ of new enrollees. When I asked faculty members why they thought women's numbers were rising so dramatically, answers tended toward noting that such statistics change from new class to new class of students. Conversations with female students, on the other hand, emphasized that continued graduate study in any field often allowed young women to delay getting married, even if only temporarily. University admission is officially described as per merit and government reservation policies, but at the time of the fieldwork I met very few students from the social categories officially considered "reserved." The academic profile of students tends to be strong, with most having achieved a position in the "first class" as undergraduates. ${ }^{4}$

At first glance, RSIEA's degree program in Environmental Architecture looks extraordinarily ambitious, perhaps so much so as to be quite unrealistic. A wide range of courses not only covers basic concepts in the ecosystem and environmental management sciences, but also an extensive array of environmental topics in design technologies and techniques, information systems for landscape analysis and mapping, law and policy, and the social sciences. A quantitative methods course is included in the required curriculum, as are group field projects and a fully independent final thesis. In addition, RSIEA regularly organizes and hosts 
public programming that explores contemporary questions in environmental design. The Institute's location in Mumbai allows it to draw from differently trained and positioned voices to address questions of urban sustainability, urban development, housing, green building techniques, and policy reform. While far from the most prestigious architecture graduate program in Mumbai or in India, the Institute is widely recognized as the first of its kind, and is in this sense a path-breaking pioneer.

Like its students, the core and visiting faculty are also practitioners in their relevant fields. Their demographic and cultural composition varies from year to year, but during my field work period the faculty's male-female ratio hovered in an almost even split. Instructors were of various ages, from early thirties to late sixties, and their cultural backgrounds included Gujarati, Marathi, Tulu, and Muslim. In addition to teaching together, several faculty members also practice professionally in the context of the Institute's Research and Design Cell, which regularly serves as a source of case studies used in RSIEA courses. ${ }^{5}$

How does one forge an environmental steward from a practicing architect? More precisely, and consistent with the Institute's stated mission, how does one assemble a pedagogical bridge between conventional architecture and its environmental alternative? As the first program to attempt to build that bridge in India, it seemed important to understand where RSIEA came from and the logic that brought its founders together.

Tracing the Institute's genesis narrative might begin with its founding scientist, now a senior core faculty member. A modest and observant man in his sixties, Dr. Ashok Joshi holds a master's degree in zoology and a Ph.D. in environmental science. He has never received formal training in architecture, yet he described the earliest germs of the RSIEA idea as the product of his conversations with architects about the absence of an integrative way of thinking about ecology and built space in Mumbai. Recounting his personal intellectual and professional trajectory, he described a specific kind of learning that he experienced in settings which brought multiple disciplinary approaches to environmental questions:

When I was doing my master's degree, we had a scientific program that was overseen by the United States National Science Foundation . . . it involved students from different departments and ... we took up the issue of pollution. They said that this was an integrated subject; it cannot be (addressed) by (just) one department. So it involved botanists, chemists, zoologists, and people from all different branches of the sciences.... (From) that I learned ... the basics of environmental studies. And then for my Ph.D. I took up an environmental problem: the effects of pesticides and human wastes on fish . . . From 1976-82 I was working as a scientist on two different projects dealing with ecological impacts. ... Around that time, one of my friends, an architect, started discussing the environmental aspects of architecture. He would 


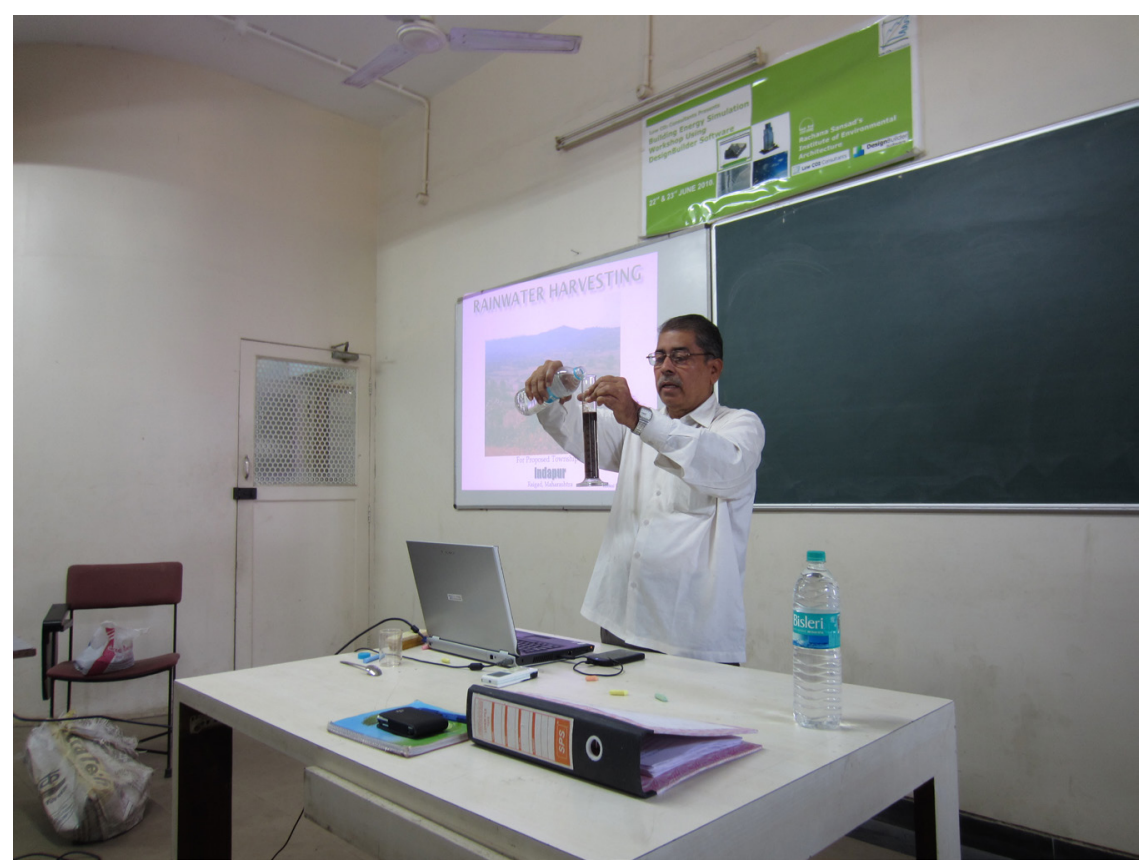

FIGURE 2. Dr. Joshi delivers a lecture on rainwater harvesting in an RSIEA classroom. Photo by the author.

ask me questions about plants, water treatment, or ventilation . . . and when I asked him why (he had not learned these things) in his architecture training-you know, at least some basic things about the environment-he said, "well, it's just not part of it." I understood very clearly then that there was a huge scope for architects to learn about the environment. So we combined his architecture knowledge and my ecology knowledge and we came to Rachana Sansad. We asked them if we could start a course, and we proposed it to the Maharashtra State Board of Technical Education.... Eventually we framed an entire (curriculum) and the Board gave us permission to give a diploma. ... So for about three years we were giving this as a one-year course. ${ }^{6}$

Soon the one-year program became a two-year, master's degree-granting program. He continued:

For three years we did that course, and after that the YCMOU (the accrediting university) expressed an interest. So we expanded the course and (curriculum) and got approval for a master's degree-two years. ... Initially we had only two students, but when it became a master's degree, we had an intake of twenty.?

The program was first offered in 2002, marking a shift in formal architectural pedagogy in Mumbai. Prior to this program, there was no codified way to undertake formal architectural study in India that focused on how architectural approaches 
and practices intersected with the environment as, in Joshi's words, " . . . an integrated subject."

Since creating that integrated subject can risk undermining the explanatory power of the knowledge forms it combines, our conversation turned to the obvious challenge of providing adequate coverage of the vast intellectual terrain signaled by the idea of the environment as "an integrated subject." Joshi explained that the key was to assemble many voices of specialized expertise, and to build a curriculum that amplified one focused voice at a time. The functionality of the curriculum thus relied on identifying and hearing from those specialized perspectives by drawing from the extensive social and professional network each founding faculty member maintained. Joshi explained:

We knew we would need scientists from many fields, and fortunately in Mumbai we have several. ... We had good social contacts. We knew excellent, experienced people. And we employed several experienced people who are working in the field to teach different courses. And more fortunately, people were also interested in coming and sharing that knowledge. I actually can't say why, because monetarily it was not at all remunerative, but somehow-is it is out of luck?-for example, one Dr. Latoo, who is renowned in botany, came regularly to give lectures about plants. And Arbinash Kubal, whom you know is the expert of Maharashtra Nature Park, he ... also came. It was like that. For geology and geography, the head of the department at Bombay University came. These are very (senior) people, very, very experienced. They came. Regularly. Like that we had more than fifteen resource persons who would come and teach specialized courses and lectures. ... My responsibility was teaching the course that gave the basics of ... ecology.... Once the ecology concepts are clear, only then can you apply them to architecture. ${ }^{8}$

The pedagogical strategy depended in part, then, on the place of its founders in that same social network of environmental specialists and practitioners, the "good social contacts" who could provide positioned expert voices to be aggregated through the curriculum itself. Guided by the RSIEA's specific Environmental Architecture curriculum, students would cultivate the skill of weaving together specific knowledge forms, and discern which were most critical for a given environmental design decision. In this way, ecology in practice in the form of environmental architecture involved mastering a strategy for assembling expert views deemed relevant, and distilling those views into architectural ideas, plans, and drawings.

But Joshi's comments pointed as well to the forces that compelled the members of his social-expert network to participate as contributors to this integrated learning endeavor. Clear and consistent financial gain could not explain their participation; for Joshi, it pivoted instead on shared devotion to a vision of integrated environmental architectural practices that could create positive ecological outcomes. Teaching was a primary way to promote and enact this vision.

The M. Arch. (Environmental Architecture) degree is today a two-year master's degree program that is conducted, as its brochure and website convey, in 
"full time face-to-face counseling mode over four semesters of 15-18 weeks each (with approximately twenty hours of contact sessions per week)." 9 Students who have earned a B. Arch. or its recognized equivalent are eligible to apply. The curriculum evolved slightly over the course of the project, with a revised course program differentiated as the "new syllabus." In both the previous and the newer curricular formats, students complete courses across a vast interdisciplinary landscape; they move between theory and practice, quantitative and qualitative modes of data measurement and assessment, and wide analytical techniques at various spatial and social scales. This remarkably broad course structure also covers specific laws, policies, and metrics that govern conventional and environmental architecture in India and worldwide. Even in its earliest form, the program is an ambitious curricular attempt to forge and teach environmental architecture as "an integrated subject."

If the vast content prevents students from developing rigorous theoretical or methodological depth in any one disciplinary arena, it nevertheless exposes them to a wide range of intersecting issues that fall under the general conceptual rubric of ecology. In a more contextualized way, it also traces a set of expert figures active in Indian environmental research and management: the same social-professional network from which Joshi drew to run the nascent curriculum remains a major source of visiting faculty members who staff courses each year. The integration, then, extends beyond the curricular content of a subject area called environmental architecture; it populates the integrated subject field with a set of practitioners to whom students not only attribute the status of an expert, but also with whom the student might be inclined to confer once graduated and practicing in the field. Joshi framed this in terms of simultaneously knowing the limits of the architect's capacities and cultivating the skill to discern the quality of knowledge derived from fields outside of architecture:

In this program they get a total understanding and they learn their limitations. They learn that they cannot do everything on their own, so they learn how to get resources-from where can they get the right (information) to give you, say, an example of responsible wastewater treatment or good solid waste management. These are both specialized fields that we present-not in detail, but how to get the exact things you require for your project. They learn that they must evaluate whether the solutions specialists offer are correct or not, good or not. They must know how to test them. So our focus is on making them understand these things on a larger scale, to evaluate according to the principles of ecology and the environment. ${ }^{10}$

There was a tension, then, between imparting the importance of consultation among a network of appropriate experts, and cultivating the capacity to "evaluate whether the solutions specialists offer are correct or not ..." As I moved through the RSIEA training experience, it became clear that we were simultaneously learning to forge a strategy for aggregating diverse knowledge forms, and to determine 
which knowledge forms mattered and to what degree. This evaluative authority derived not from a position of commensurate skills and training, but rather from the distinctive expert position of the environmental architect: a good environmental architect possessed and employed a capacity to think across the range of scales and biophysical processes that environmental architecture signaled. These might encompass biophysical and social details relevant to a building site, its broader biophysical and social context (such as a watershed or a bounded city), and a site's interconnection with processes that nested those scales into even wider contexts (such as an entire river system or a demographic migration pattern). Here, we might characterize the curricular mission as fostering the capacity to think in an "integrated" way across disciplinary and scaled perspectives, and to privilege this capacity over, for example, specializing in aquatic chemistry, urban sociology, or so-called conventional architecture. These green experts were first and foremost integrators; they were not architects who had mastered environmental science or social science or both. The sources and types of knowledge they would integrate, and the frameworks through which the quality of that knowledge was deemed acceptable were critical. At RSIEA, that framework was often shorthanded simply as "good design."

Learning to discern and undertake good design was a key intended outcome not only of the formal experience of the curriculum, but also of the social experience of collective learning and application. As faculty and students forged and experienced the shared conceptual space of good design, they came to share a collective, cultivated environmental subjectivity that valued and sought to elevate the Institute's specific approach to the built form. ${ }^{11}$ As both an integrated-that is, interdisciplinary-subject and a collective social experience of learning good design sensibilities, then, the "integrated subject" produced an integrated subjectivity. Tracing and examining this subjectivity, and noting the environmental affinities through which it operated, is part of the work of the chapters to come, but let us mark here Joshi's characterization of the impulse to name, define, and employ "good design," and its attachment, via the RSIEA curriculum, to existing networks of expert knowledge.

Another important dimension of the RSIEA mission was the perhaps less tangible, but nevertheless central, notion of devotion or commitment. This was at times described to me in equally integrated terms, in the sense that teaching environmental architecture and being an environmental architect were part of a "totalizing" lifeway. Clear lines between vocation and job, personal and professional, or work and politics were always elusive. Faculty, and occasionally students, invoked their strong commitment to environmental architecture and its potential outcomes in order to explain, perhaps far better than Joshi's characterization of it as "luck," why such reputable scholars and practitioners would detach their work for RSIEA from direct and fair payment for their service. Such "commitment" was not exclusive to guest lecturing experts who might forego an honorarium; I regularly 


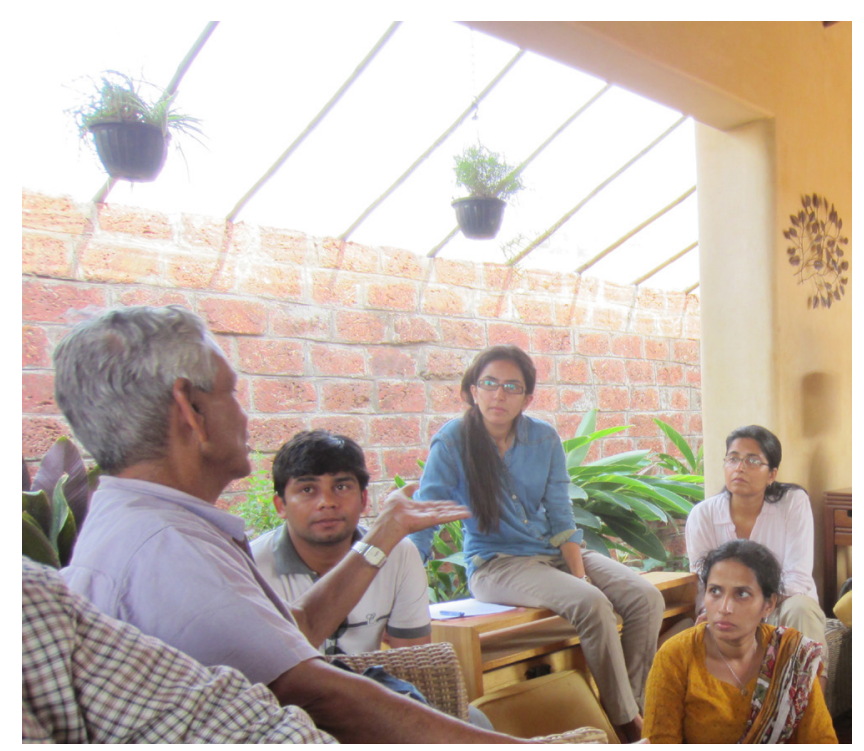

FIGURE 3. Dr. Latoo talks with RSIEA students during a field study visit. Photo by the author.

noticed faculty members devoting considerable personal time to students, to course development, and to the Institute. Few voiced open concern for quantifying the hours spent or enumerating tasks performed, and the few I observed who did tended not to remain with the faculty.

An interconnected set of exclusions and self-selections are therefore also apparent here. Those who undertook the committed practice of teaching at RSIEA were often, though not always, already identified as experts within a specific socioprofessional network, and some were also occasionally able to forgo payment (or accept a smaller amount than might otherwise be offered) for hours worked. While these were not universal attributes for every faculty member, they figured prominently, and were certainly central to the early life of the program.

One morning in July 2012 I arrived at the Institute to find the core faculty filing out of a meeting room. Their faces were unusually somber; some bowed their heads. Something had clearly transpired to produce collective disappointment.

I learned a few hours later that a curricular evaluation session with representatives from the Council of Architecture Certification Board had returned some unwelcome news. In response to growing enrollments, the Institute sought to activate a revised curriculum that would facilitate certain forms of faculty and 
programmatic expansion. Yet the Council had rejected their proposal on at least two grounds.

Up to this point, mid-2012, work and excitement surrounding the Institute's expansion had been part of the everyday atmosphere among faculty. Countless hours, meetings, and discussions had brought the collective project of developing a new curriculum into the center of an already crowded workload, but people proceeded with confidence that a new course and scheduling sequence would enable more in-person contact between students and faculty, and more effective experiential learning. The new curricular design would place stronger emphasis on individual student projects, and culminate in an independent final thesis. New policies would make course attendance compulsory and admissions decisions wholly merit-based. Although faculty members voiced a commitment to keep tuition fees at a level competitive with like programs in Mumbai, it was clear that new teaching staff would have to be hired, and so a tuition increase was imminent.

Having witnessed doubled enrollments over only a few years, enacting these changes carried a certain urgency. But the impasse at the CoA meeting seemed to indicate that something had gone wrong; institutionalized structural requirements had somehow clashed with the program expansion proposal.

After everyone had settled back at their desks or rushed off to classrooms, I shuffled into Roshni Udyavar Yehuda's office. She explained that the CoA objections related to violations of some of the basic requirements for academic degree programs in any kind of architecture in India. The first objection was that current Institute faculty were not paid the Council of Architecture's regulation salary, and in order to hire new faculty, all compensation levels would have to be adjusted to those regulation levels. Even with proposed tuition increases, Yehuda explained to me, this was completely unfeasible. "We simply can't afford it," she said plainly.

The core issue was more than a matter of budgetary calculus, however. Yehuda lamented that reducing the value of teaching environmental architecture to its price in INR diminished what was an otherwise expansive endeavor "far beyond economics." She repeated that the RSIEA faculty had, since its inception, taught "out of devotion to the subject,"12 emphasizing that the faculty had never joined because of the lure of the salary. Furthermore, she argued, "How can we say that someone who makes less in salary is less competent, or less valuable? By that score a volunteer, or someone who comes for the sheer passion of the teaching, is automatically not competent in the eyes of the CoA." ${ }^{13}$ Her voice betrayed exasperation.

She continued: "It's the culture of this program that we teach here because we are committed to the subject. The salary is not a measure; it has never been the reason we teach this." ${ }^{14}$ While for her this was a way of ensuring that those who taught at RSIEA were fully committed to the mission, it might have also prevented those without prior material security from considering it, regardless of their passion and commitment. 
Yehuda's reaction to the Council's concern arose in large measure from a frustrating collision with the structural limits of what, up to that moment, had been a differently regulated collective space, one centered on a shared willingness to accept benefits other than money in exchange for environmental architecture teaching work. There existed no metric for capturing, conveying, and affirming this kind of value for the Council, leaving the faculty "devotion" so central to teaching at the Institute supplanted by a more powerful, if external, regulatory protocol. The failure of monetary metrics to capture the myriad forms of value represented by the environment is a longstanding theme in environmental studies; indeed, the problem of "commensurability" forms an important basis for a wide array of critiques in political ecological theory. ${ }^{15}$ In this instance, the externalities were social. Yehuda lamented the absence of adequate metrics for seeing and valuing a collective social mission; while faculty members were officially laborers, they were socially fellow devotees. Of course, in the eyes of the CoA, such conditions simply constituted labor exploitation, and could not proceed.

A second Council objection underscored the incommensurability of the "integrated subject" and the CoA's measures of professorial fitness and curricular integrity. Regulations defined faculty eligibility strictly according to degree status, such that appointed faculty must hold degrees in architecture. Perhaps ironically, this disqualified nearly everyone on the faculty and left only three core faculty members. Despite accomplishment or expertise in their given disciplines, most professors could not, by this definition, remain eligible to teach at RSIEA. Again, the regulations presented a structural obstacle to a core principle of the integrated subject: "Our strength and uniqueness is the fact that this program is not only one discipline. We depend on that," Yehuda said. "Its entire future is threatened now." I asked naively if anyone had expected this challenge to the Institute's expansion proposal. The response was a troubled, almost blank stare. "No."16

The integrative improvisation that had marked the Institute's inception and so much of its history was possible at a different scale, with smaller enrollment numbers. Bustling enrollments, ever-growing demand, and the expansion of the professional field itself re-scaled the undertaking so as to render it more legible to institutions whose principles of value and indicators of merit clashed with what Yehuda called RSIEA's “culture." With legibility came new layers of scrutiny, potential sanction, and frictions between an idealized, integrated learning domain and the regulatory structures that extended from the political economic context beyond Rachana Sansad.

Many RSIEA faculty members brought to that moment a shared, decades-long history of creating and operationalizing their vocational curricular mission. Udyavar Yehuda's reference to "devotion" captured a prevalent characteristic of their interactive mode as colleagues and as teachers. Many were also constant 
collaborating practitioners and close personal friends. Their work together was often organized in professional terms, but also functioned between with the many textures of sociality: close friendships, shared projects, and the ubiquitous shared mission made it difficult to regard RSIEA faculty as simply a collection of environmental architecture teachers. Indeed, at times these social textures could be accurately framed as quietly political-a kind of professionalized, but tempered, environmental activism.

In addition to teaching, a subgroup of RSIEA faculty worked as practitioners under the auspices of the Institute's Research and Design Cell. ${ }^{17}$ On a day spent walking the urban landscape together in the Matunga neighborhood of Mumbai, Yehuda remarked to me that between teaching together and working on projects together, the faculty was "practically like family." ${ }^{18}$ In a separate meeting months before, she'd mentioned with pride that India's Outlook magazine had recently ranked Rachana Sansad fifth among architecture academies in India. What made RSIEA completely distinctive, she told me then, was its faculty and their extraordinary commitment to the subject and the mission. "We work together in every way," she said at that time; "We're like a functioning family."19

Many faculty members repeated strains of this sentiment; the shared mission reinforced the quality of the personal and professional relationships through which it was enacted. Their devotion to the integrated subject reflected an integrated subjectivity, albeit in a different register. At the same time, we rarely spoke of the few faculty members who joined the faculty during my research but decided to leave. That they existed reminds us that the interpersonal and professional affinity, and the standards of "devotion" and commitment were neither automatically desirable nor universally possible to meet.

But how and when does one move from the more bounded category of a qualified teacher of some aspect of environmental architecture into the "totalizing" lifeworld of RSIEA's “integrated” subjectivity? When I asked the Program Head when she first began to sense that for her, environmental architecture would transcend a simple job, she traced her response to a single figure from her past. Decades earlier, Yehuda had worked with an organization headed by the Indian environmental activist Rashmi Mayur. Mayur was the founder of India's International Institute for a Sustainable Future, and had served as an advisory figure in the key UN Meetings that had shaped the international environmental policy agenda in the early nineteen-nineties. This was a time of new forms of environmental thinking and discourse at the international scale; emboldened by the formulation of sustainability espoused in the pivotal Bruntland Report, landmark meetings like the first Earth Summit in Rio de Janiero (1992) and the Habitat Summit in Istanbul (1996) carved new concepts for understanding the interface of environmental change and socioeconomic development. A wholly reworked agenda for global-scale issues 
including poverty alleviation, biodiversity preservation, and environmental conservation followed in their work. Mayer was present and active in international environmental policy circles in this moment, and Yehuda recalled her experience of working with him as deeply formative.

In a letter to me that accompanied a gift copy of Survival at Stake, the anthology of Mayur's work that she co-edited with a colleague in 2006, Yehuda described him as:

... known to everyone-from the Prime Ministers of several countries to villagers. He was very popular, as he had worked on some major environmental movements, including the Bhopal Gas Tragedy, and he was responsible for the closing of some large polluting industries. It was on the invitation of Indira Gandhi some time in the early 1970s that he came back to India after completing his doctorate studies and joined as Director (of the organization). ${ }^{20}$

In her introduction to Survival at Stake, she called Mayur a "visionary" whose:

... spirit lives on in the souls of thousands whom he inspired to tread his path. Popularly known in India as the "doomsday professor," Rashmi Mayur prophesied that if human beings continue on their present reckless path of mindless development, the earth's ecological systems would collapse and the human race will become extinct. (He wrote) "The consequences of the war that has been waged against this planet for the last two hundred years by human beings, may be that we may have no human inhabitants in the future." However, unlike many crusaders who relinquished hope and left the battlefield, and others who refuse to recognize the symptoms of a diseased planet, Rashmi loved it enough to see it with the eyes of truth. He was too optimistic to be biblical. "Nonetheless, we cannot be immobilized by the ugly reality. As long as we are alive, as long as we have vision and as long as we think of the future of the earth and our children, we must hope that sanity and wisdom will prevail.".21

The essay continues to narrate Mayur's basic biography, and emphasizes in particular his place as a "world citizen" whose commitment to amplifying environmental causes had lasting effects in India.

That RSIEA's Head traced her own devotion to her work with a distinguished environmental activist in India and at the United Nations is consequential for understanding the form and mission of the Institute itself. The challenge to which RSIEA's version of environmental architecture was a response was, as noted, a "war that has been waged against this planet for the last 200 years"; overcoming that war required a professional commitment that could transcend the considerable labor it implied. Thus Yehuda described total commitment as central to making RSIEA faculty work meaningful; its consequences did not end with the individual students who would train there. They would extend to fulfilling her own role in combatting the ecological problems that in her own generation had only worsened. Her work simply followed Mayur's example, she told me, in which responsible environmental work was accomplished only when it was enfolded in one's sense of identity. She described her work as ideally reaching far beyond the 
classroom, perhaps influencing, if even in a very small way, environmental conditions in India, and perhaps even the broader world. The sometimes-India-specific, sometimes-globally-focused RSIEA curriculum reflected this almost nested sense of the environmental architect's mission: however remotely, it was connected to a global environmental crisis and its appropriate suite of solutions. It also seemed to underline a rather crucial sense of defiant hope, here elaborated as a refusal to be "immobilized by the ugly reality." It was only through such refusal-enacted as ecology in practice-that the environmental architect could maintain the capacity to both envision and operationalize a future of good design.

The "ugliness" of present conditions was quite real, and the challenge they signaled immense. Mumbai's staggering growth projections, extreme air and water pollution, deep and enduring asymmetries in housing conditions and material wealth, and a multi-faceted but oft-repeated story of urban development in exclusive service of land speculation, coastal degradation, and rampant disregard for human rights or ecological concerns made the very suggestion that architects-or any other collective of urban professionals who sat on the margins of the nexus of urban development power-could have an impact on the city's environmental present and future at best naive and at worst perhaps destructive. My everyday conversations in Mumbai regularly cast doubt on the actual "real world" potential of a collective of architects studying environmental design. How, I was repeatedly asked, could figures other than builders, bureaucrats, and politicians influence the development trajectory of Mumbai?

Yet from a social position inside RSIEA's world of good design, I learned to see a persistent and almost dismissive confidence. Obvious and tenacious obstacleshistorical, bureaucratic, political, economic, and geographic-could either give way, or were already giving way, to positive change. To my voiced expression of doubt, Dr. Joshi assured me that a real and discernable architectural-environmental change was in fact already happening, but in order to see it, one needed to adopt a historical perspective. With halting optimism, he met my skepticism with a personal sort of evidence, one anchored to a certain view of the arc of urban development in Mumbai:

What I have seen is that demand (for environmental architecture) is improving, and scope is improving. But you have to learn to see the changes; they may not be what you are expecting. There are many (increments), some of which are very small. Like providing a place for waste processing or using a certain design aspect to improve the quality of ventilation or light. And today the changes are there: people in Mumbai are more aware and conscious of the environment. They are willing to do new things.

Still unconvinced, I asked whether these incremental changes were sufficient to open the kinds of opportunities for practitioners of environmental architecture 
that would yield both power and autonomy (two things quite clearly missing in the Mumbai of the present). In response, he repeated the entreaty to "see" in a particular way-to notice attributes of change that escape the metrics and usual framings of maldevelopment in Mumbai.

What is happening is that the number of environmentally certified buildings is very few. But this is because it involves cost and some of the requirements are difficult to meet. However, many builders are including more individual (environmental) features, like recycling water and using it for flushing or for terrace gardens and vertical gardens. Or like keeping more open space. . . . These small aspects are being implemented, but (builders) are not going for certification because it requires lots of things-use of nonconventional energy or energy-efficient equipment, and things like this. At least you can say that $50 \%$ of what is required for a green building is being implemented on a regular basis in Mumbai. And environmental architects are very important here.

More importantly, he told me, the scope for future environmental design opportunities was improving because Mumbai's specific urban-cultural sensibility was in part about example-setting, and in part about taking risks. In the context of India, he suggested, Mumbai is a city unlike any other; here, a portion of the public had the capacity to invest in the things they wanted, which increasingly included environmental vitality. He referred, of course, to only an elite subset of Mumbai's wider population, but within that subset Joshi saw qualities specific to the city. This logic placed Mumbai in a powerful cultural and economic position to adopt patterns of environmental improvement as evidence of progress. He explained:

People in Mumbai have money power. They are willing to spend money and become an example. The culture in this city is entirely different (from the rest of India). They don't bother worrying - if a client in Mumbai decides, "I want this," then they go for it. . . Outside Mumbai, (most) people are not that ready to spend money. They are more conservative and frugal. Mumbai has got tremendous purchasing power. ... And also, people talk... They may not go and look and study an issue themselves ... but whatever a hundred people are talking (about), they will talk about the same thing. And I personally have worked with many projects in which it is clear that mentally people in Mumbai have already accepted this concept of the need for green buildings. And whatever is possible they want to do.... So there are good things you can see, and the willingness is there. Clients say, "if you give us the good and foolproof technology and ensure that no problem will be created by this design, we are willing to accept it." The spaces are constrained in Mumbai, but money and willingness are not a concern. The scope for environmental architecture here is good, and it is getting better and better.

For Joshi, then, the same forces associated with the city's urban development dynamics-greed, power, and conspicuous consumption-could be construed 
as sources of hope; indeed, these could be understood as real-time evidence that environmental architecture was taking root and would eventually flourish.

Through convictions derived from a shared, integrated subjectivity and devotion to an integrated subject, RSIEA's faculty worked and taught in ways that both depended upon, and yet quietly defied, Mumbai's urban political economy and development trajectory. Joshi's logic of "money power" even construed the political economic status quo as central to his logic of change; the very force that had driven so much ecological destruction could be imagined as its own undoing. Over time, I came to realize that Joshi was not alone in his full expectation of dramatic shifts, not only in urban development patterns and built forms, but also in the political economy that suspended them in its web.

Through curricular design, shared architectural practice, and modeling an environmental architectural community that was the discernable product of their work together, the core faculty of RSIEA sought to train, inspire, and support the architects who would forge the good design of a better urban future. The environmental architect could not be an expert in every disciplinary dimension relevant to good design, but by learning to see an interconnected system of processes and considerations, she would ideally be prepared to identify, assemble, and critically assess the diagnostic work of socioenvironmental reinvention. This integrative sensibility formed the core of producing design prescriptions worthy of the good design designation. RSIEA's formulation of environmental architecture thus promised to turn the destruction of conventional architecture into the promise of stewardship. Teaching it as a vocation allowed its adherents a sense that they were transforming architecture itself from environmental destroyer to, at the very least, its benign enhancement, and at the very best, that same destruction's direct socioenvironmental remedy. 